\title{
Finite Element Analysis of IPN Reinforced Woven Fabric Composite
}

\author{
Suresh $\mathrm{G}^{1}$, Jayakumari L S ${ }^{2}$, Dinesh Kumar $\mathrm{S}^{1}$
}

\begin{abstract}
${ }^{1}$ Department of Mechanical Engineering, Rajalakshmi Institute of Technology, Kuthambakkam, Chennai.
${ }^{2}$ Department of Rubber and Plastics Technology, Madras Institute of Technology, Chennai, Tamil Nadu, India, +919444328611, e-mail: saisuresh1979@gmail.com
\end{abstract}

\begin{abstract}
A series of E-Glass fiber reinforced polyurethane (PU)/vinyl ester(VER) resin interpenetrating polymer network (IPN) composites were prepared. The Mechanical Properties like tensile, flexural and impact of IPN composite were studied. Results revealed that addition of PU increases the impact strength by $8.33 \%, 7.69 \%$, $14.28 \%, 12.5 \%, 11.11 \%$ for the proportinate of $0 \% \mathrm{PU}, 10 \% \mathrm{PU}, 20 \% \mathrm{PU}, 30 \% \mathrm{PU}, 40 \% \mathrm{PU}, 50 \% \mathrm{PU}$ respectively, at the slight expense of decrease in flexural and tensile modulus. The obtained experimental results were compared with the Finite Element Analysis data's (ANSYS 10). The comparison shows good agreement with experimental data's.
\end{abstract}

Keywords: IPNs, E-Glass fibre, Vinyl ester, Polyurethane, ANSYS - 10.

\section{INTRODUCTION}

Interpenetrating polymer networks (IPNs) are polymer alloys, which consists of two or more polymers in a network form that are held together by permanent entanglement. Instead of giving much effort to give change in the chemistry of polymer structures, the way of mixing of one polymer alloy with another alloy shows the increase in all aspects of mechanical property. This IPN system shows excellent property than the Individual (single) components, as well the individual specific characteristics of the polymer are extracted in such a way to achieve or meet our the requirement of the present day industries[1-4].

In the recent year's vinyl ester resin (VER) have captured very good market in the area of pipes, tanks, ducts manufacturing industries because of its chemical resistance and low-cost. Especially in the area of manufacturing of chemical storage tanks and pipes, it is been very widely used and accepted as the universal one. Besides that it's applications are extended in the area of coatings, structural applications, adhesives, etc. Since it had very good cure control rate, it proves itself as the best alternate and replacement of epoxy resins in many aspects. It is used as coatings in circuit boards and conventional concrete materials [5-7].

The another one polymer which is been very widely used in most of the industries are polyurethanes (PU) because of its versatile elastomer property, its application are extended because of its very good load bearing capacity, flexibility, abrasion resistance, resistance to oil, water \& grease and it exhibits better electrical insulating property. In the recent years, polyurethane usage has increased tremendously in the area of automotive industries to manufacture various parts and considered as the best replacement for traditional rubber bushings which is very prone to salt wear and chemical debris. The Flexibility, durability property of the PU is been very properly tapped in the area of manufacturing the products like bumpers, roll pans, side skirt and wiper cowls [8-9].

Vinyl ester resins have been employed in production of high temperature chemical carrying pipes like ducts and storage tanks. However, it is generally a brittle polymer, which restricts its application to limited area. On the other hand, the PU is very (visco elastic) flexible polymer, with low mechanical strength, but has very good viscoelastic characteristics. In order to bring together the advantageous part of both the polymer, the IPNs are formed. Many attempts so far have been done by many researchers in this area to grab the best property of the individual polymer in the name of blending one polymer with another one in the name of IPNs [9-11]. To employ the IPN composite in exact usage, it needs the rigorous testament. Moreover, the experimental investigation alone is not that much sufficient to replace this material for commercial usage. So in order to evaluate the mechanical characteristics of this material it needs the analytical evaluation as well because, it has the anisotropic property and complicate structure. Hence in this paper, the modeled specimen was analyzed by using commercially available finite element analysis software (ANSYS) [12-19]. 


\section{MATERIALS AND METHODS}

\subsection{Materials}

VBR 4508 VINYLESTER RESIN was obtained from Vasavi Bala Resins (P) Ltd. Chennai. Polyurethane (CG-60A Commercial Grade based on TDI System) was purchased from Cross Link Technology. All the chemicals were used as purchased during investigation.

\subsection{Sample Preparation}

Plain woven E-Glass fabric $\left(350 \mathrm{~g} / \mathrm{m}^{2}\right)$ was used as the reinforcing materials in the VER/PU Interpenetrating polymer networks. The resin vinyl ester, MEKP (methyl ethyl ketone peroxide), and cobalt naphthalene (CO) were used as initiator and accelerator respectively. The varying percentage of PU $(0 \%, 10 \%, 20 \%, 30 \%$, $40 \%, 50 \%$ of PU) with VER were mixed in different proportions, then the MEKP of $1.5 \%$ was added and the mixed blend was continuously stirred for 20 minutes.

Plain woven glass fabric were cut into definite shape and size and kept in the oven at $150^{\circ} \mathrm{C}$ to remove the moisture. A silicone release agent was coated over the steel mold and a layer of resin was applied over with brush, then the first layer of the glass fiber was placed over the resin and rollers were used to unite them. This stacking process was continued to build a 5 layer of laminate to get $3 \mathrm{~mm}$ thick composite plate. Once the composite was made, the specimen conditioned at a period of 24 hours. The composite was further post cured at $80^{\circ} \mathrm{C}$ for $2 \mathrm{hrs}$ in a hot air oven for complete polymerization.

Table 1: Typical combination of IPN - Formulation

\begin{tabular}{ccc}
\hline SAMPLE NO. & VER (gms) & PU (gms) \\
\hline 1 & 100 & 0 \\
\hline 2 & 90 & 10 \\
\hline 3 & 80 & 20 \\
\hline 4 & 70 & 30 \\
\hline 5 & 60 & 40 \\
\hline 6 & 50 & 50 \\
\hline
\end{tabular}

\subsection{Test methods}

FTIR spectra of IPN composite were recorded between $400-4000 \mathrm{~cm}-1$ with a Perkin Elmer FTIR Spectrometer with a KBR pressed pellet. The samples of IPN were kept on the ATR attachment and a minimum of scans were averaged with a resolution of $2 \mathrm{~cm}^{-1}$. During this course of study, characteristic absorption peaks of functional groups were detected and monitored. By using Universal Testing Machine (Instron Model) the mechanical properties of E-Glass fiber reinforced IPN were investigated. The tensile test procedure was followed as per ASTM D 3039 [9-10].

The test piece was maintained to the dimension of $250 \mathrm{~mm}$ x $25 \mathrm{~mm}$ x $3 \mathrm{~mm}$ (length $\mathrm{x}$ width $\mathrm{x}$ thickness). Besides that, the flexural test was also carried out as per ASTM D790-03. The flexural test pieces were cut to the size of $127 \mathrm{~mm}$ x $12.5 \mathrm{~mm}$ x $3 \mathrm{~mm}$ (length $\times$ width $\times$ thickness). The cross head speed was maintained about $2 \mathrm{~mm} / \mathrm{min}$. Similarly the impact strength was also analyzed for all the proportions according to the standard of ASTM D256. The dimensions of the samples were $63.0 \mathrm{~mm}$ x $12.8 \mathrm{~mm}$ x $3.2 \mathrm{~mm}$ (length $\mathrm{x}$ width $\mathrm{x}$ thickness) [10-12].

In this manuscript, ANSYS software was used to make the numerical simulation of the IPN composite. A 3D FE model was constructed in ANSYS with the following dimensions: $127 \mathrm{~mm} \times 12.5 \mathrm{~mm} \times 3 \mathrm{~mm}$ [13]. The 8-node, 3-D Layered structural solid element (SOLID46), with three DOF per node (UX, UY, and UZ) was used in the current work to form the FRP. This element (SOLID46) enables to give the user-input constitute matrix option. Besides that it adjusts the material property in the transverse direction by maintaining the stresses constant in transverse direction. The hexagonal elements were used to mesh the composite. The meshes were divided automatically by the software. Two end was adhered and constrained as X,Y,Z translations. The boundary conditions were chosen, such a way that one of $\mathrm{YZ}$ sides was restrained in the $\mathrm{X}$ direction and a Flexural displacement was imposed on the YZ side [15-18]. 


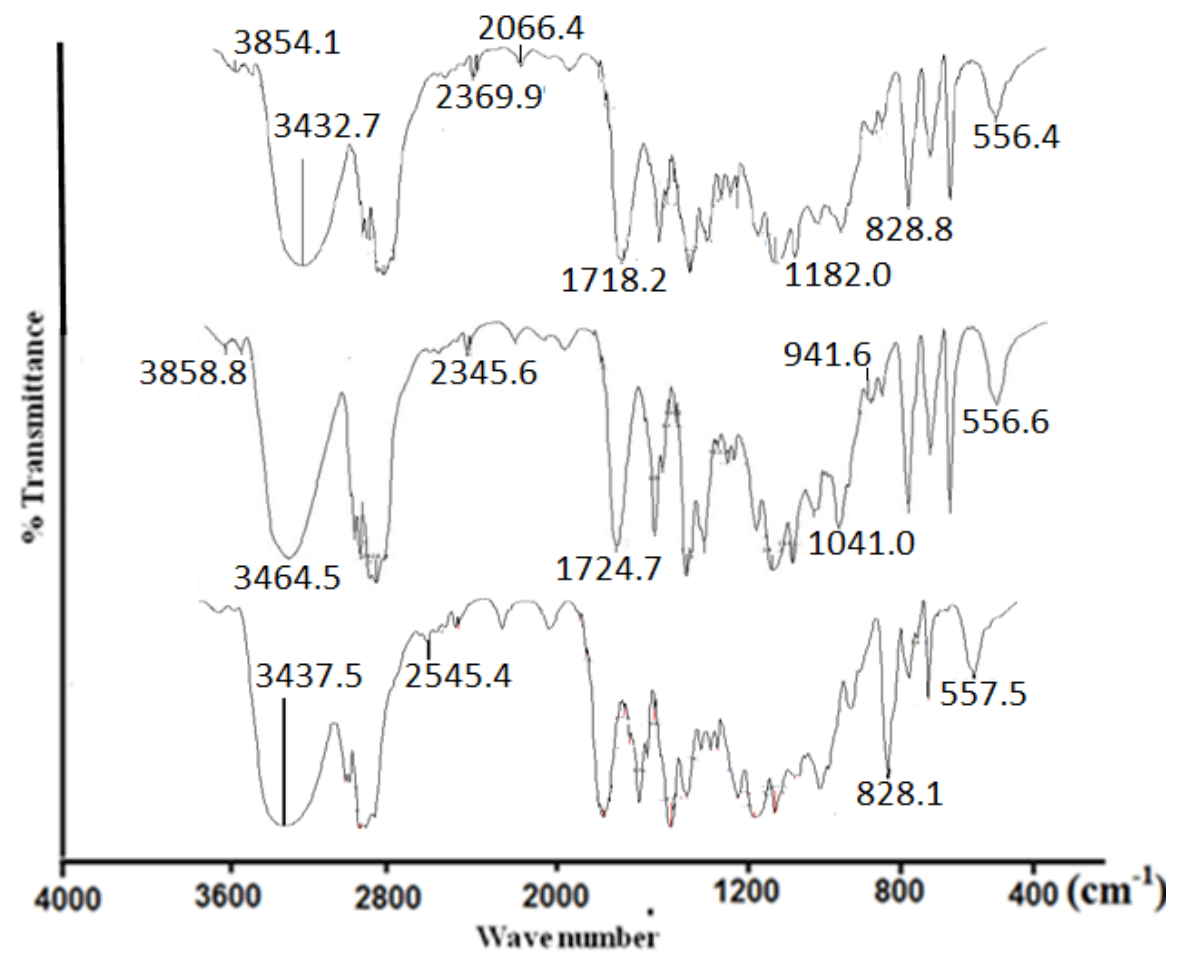

Figure 1: FT-IR Spectrum of cured IPN (a) 100\% VER (b) 10\% PU (c) 20\% PU

\section{RESULTS AND DICUSSION}

\subsection{Spectral Analysis}

Figure 1. Shows FTIR spectra of 100\% VER, 10\% PU and 20\% PU. The intensities of the isocynate peak $\left(2370 \mathrm{~cm}^{-1}\right)$, - OH peak $\left(3432 \mathrm{~cm}^{-1}\right)$ urethane peak $\left(1508 \mathrm{~cm}^{-1}\right)$ were observed during the polymerization of PU. As the polymerization proceeds the intensity of absorption peak corresponding to -NCO group (2370 $\mathrm{cm}^{-1}$ ) decreases whereas the intensity of the absorption peak corresponding to urethane linkage $(1508 \mathrm{~cm}-1)$ increases. Formation of vinyl ester resin is indicated by the peak of $-\mathrm{C}=\mathrm{C}-$ group at $1618 \mathrm{~cm}^{-1}$.

\subsection{Experimental Analysis}

The static mechanical properties like tensile, flexural and impact were performed for glass fiber reinforced IPN of various compositions and are presented. The same results were plotted in the figure 2(a) \& 2(b).
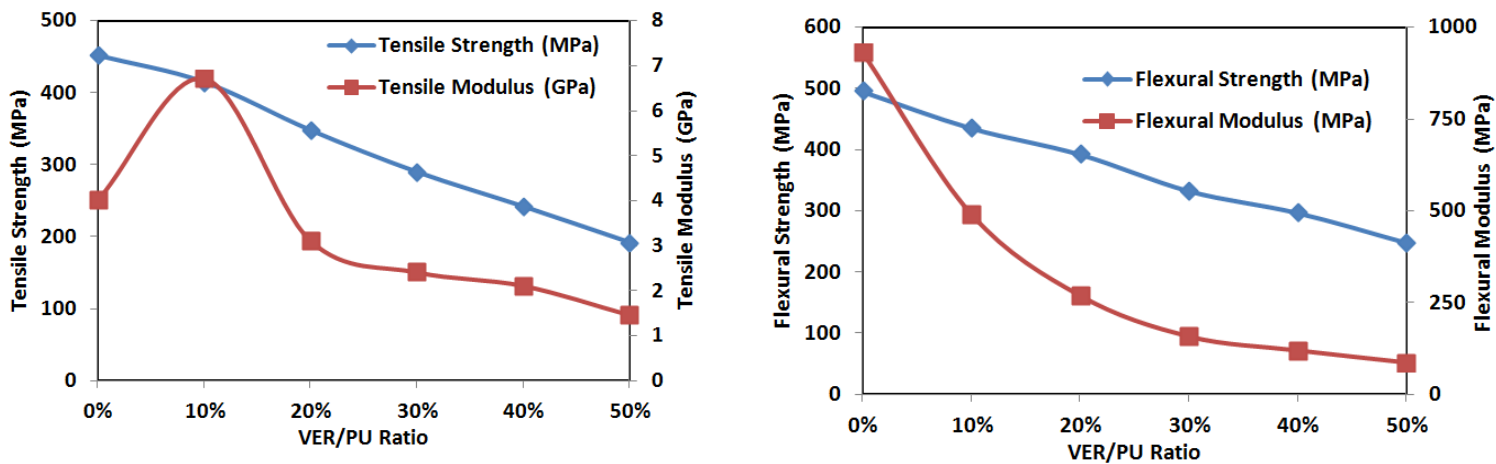

Figure 2: $\quad$ (a) Tensile strength \& tensile modulus alue of E-Glass fibre reinforced IPN laminate

(b) Flexural strength \& flexural modulus value of E-Glass fibre reinforced IPN laminate

From the figure 2(a). It was observed that Tensile strength, tensile modulus, Flexural Strength and Flexural Modulus of the VER/PU composite decreases with increase of PU into IPN system. The $0 \%$ IPN Laminate exhibited better tensile strength value of $452 \mathrm{MPa}$ as compared with remaining compositions, this value was quite high as compared with the other proportionate of PU loading into IPN system. 
Similarly the corresponding strain value of the $0 \% \mathrm{PU}$ was 0.3 . This value $(0 \% \mathrm{PU})$ was very less, when the same obtained values were compared with other proportionate of PU loading into VER matrix IPNs. The reason behind that of this phenomenon was, the entire matrix material of VER purely consisted of hard segment (HS) presence. This presence of HS (Hard segment) of VER exhibited the brittleness in nature and this leads to the failure in gauge area (pulling of fibre). This property leads to the significant reduction in strain rate as compared with the other proportionate. This HS presence was the prime reason behind that of less strain rate failure during the tensile strength analysis. Whereas the addition of PU into IPN system reduces the value of tensile strength to the greater extent considerably. Because it was found that, the soft segment characters of PU makes the proper mutual entanglement mechanism with the VER, that is the reason why, the elastic characteristic of (SS - Soft segment) of PU presumably reduces the brittleness nature of the VER outstandingly.

As high as the PU pre polymer added into the VER matrix, contrarily the addition of PU assumed to be either weakens the HS property of matrix or else induces the elongation strain rate of the composite specimen. This was mainly due to the (PU) soft segment present in the IPNs. Nevertheless, the strain rate found in the composite specimen was $0.9 \%, 1.4 \%, 2.1 \%, 2.4 \%, 3 \%$ for the consecutive proportionate $(0 \% \mathrm{PU}, 10 \% \mathrm{PU}$, $20 \% \mathrm{PU}, 30 \% \mathrm{PU}, 40 \% \mathrm{PU}$, and $50 \% \mathrm{PU})$.

From the figure 2(b) it was the evidenced that, the pure $0 \%$ specimens exhibited the flexural strength value as similar as the trend line seen in the tensile strength (high value seen, comparatively with all the remaining proportionate). Though the common findings from the flexural strength purely based on the modulus of fibre and resin, here too the specimen of $0 \% \mathrm{PU}$ subjected in the flexural test evidenced with the value of $495 \mathrm{MPa}$, with the corresponding strain rate value of $2 \%$, again as such discussed in the trend of tensile strength analysis, this value too purely resembled presence of HS - Hard segment presence into VER. Normally the E-Glass fibre surface will have very good inter-phase addition with the VER matrix material, since its possess the hydroxyl functional group on the surface, it gives immense interfacial adhesion between the both the constituents.

When PU loading started to increase in the VER (IPN System) matrix, the specimens which subjected to flexural test, exhibited the drastic change in the value of flexural strength. The values were found as $435 \mathrm{MPa}, 392 \mathrm{MPa}, 332 \mathrm{MPa}, 296 \mathrm{MPa}, 247 \mathrm{MPa}$ for the corresponding proportionate $0 \% \mathrm{PU}, 10 \% \mathrm{PU}, 20 \% \mathrm{PU}$, $30 \% \mathrm{PU}, 40 \% \mathrm{PU}$, and $50 \% \mathrm{PU}$ respectively, against their strain rate of $2.2 \%, 3.5 \%, 4.5 \%, 4.2 \%, 6.2 \%$ for their respective above said proportionate. Similar to the proof found in the fracture in the tensile (pull-out fracture), the flexural test too observes the same kind of fracture occurrence seen in the tensile test. As high as the addition of PU into VER matrix increases the different set of fracture trend which was not in the normal mode found in the $0 \%$ PU. It was not exhibited the sudden pull out fracture, instead it elongates as much as it can, based on the PU loading into the IPNs. This confirmation shows the significance of visco-elastic (PU) characteristic presence in IPN matrix. The soft segment (SS) property of the PU appreciably takes the transverse load and it avoids the pull out fracture in the specimens. As high as the PU loading into VER, it greatly reduces the fracture and maintains the structural integrity of the specimens by giving up the flexural strength. As well as, the interesting finding from the test was that, once the flexural load is taken away from the specimens, it regained its original position within the limited span of time, this phenomenon purely depends upon the PU loading, which was not seen in the $0 \% \mathrm{PU}$.

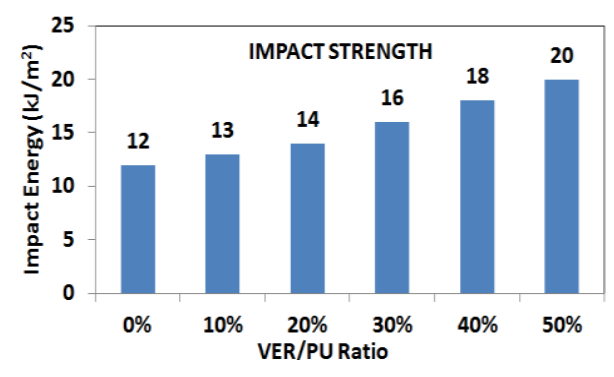

Figure 3: Impact strength values of E-Glass fibre reinforced IPN laminate

Interesting finding was observed in the impact test from the figure 3 that, the initial value found in the test was $12 \mathrm{KJ} / \mathrm{m}^{2}$ for $0 \% \mathrm{PU}$, but the value of impact modulus tremendoulsy started to increases to the higher stage, when corresponding PU loading increases into IPN system. The soft segment presence in PU played a major role in this test; it observes the maximum impact load before it get failure. The visco elastic and toughness property of the PU makes an better entanglement mechanicsm with the VER and observes the maximum amount of the energy by corresponding addition of PU. 
The $10 \% \mathrm{PU}$ loading specimens observed with the impact strength of $13 \mathrm{KJ} / \mathrm{m}^{2}$, similary $20 \% \mathrm{PU}$ gives the value of $14 \mathrm{KJ} / \mathrm{m}^{2}$, remaining proportionate as well gives the better absorption value like $16 \mathrm{KJ} / \mathrm{m}^{2}, 18$ $\mathrm{KJ} / \mathrm{m}^{2}, 20 \mathrm{KJ} / \mathrm{m}^{2}$ for the corresponding $30 \% \mathrm{PU}, 40 \% \mathrm{PU}$ and $50 \% \mathrm{PU}$ respectively. The presence of the side ester group in IPNs noticeably maintains and creates the wide the gap between the IPN molecules, by providing the enough free volume effect in bulky groups, this was the reason behind that of the energy absorption (Impact modulus), when PU loading increases [10,18]. Again this (higher toughness value) effect proves that, there was permanent entanglement between the VER and PU.

\subsection{Numerical Analysis}

The experimental results were compared with analytical results and presented in Table 2.

Table 2: Comparison between experimental results Vs Analytical Value

\begin{tabular}{ccccc}
\hline SAMPLE NO & COMPOSITION & EXPERIMENTAL RESULT & ANALYTICAL RESULT & ERROR \\
\hline 1 & $0 \% \mathrm{PU}$ & 7.45 & 9.54 & 2.09 \\
\hline 2 & $10 \% \mathrm{PU}$ & 12.55 & 17.6 & 5.05 \\
\hline 3 & $20 \% \mathrm{PU}$ & 16.58 & 19.309 & 2.729 \\
\hline 4 & $30 \% \mathrm{PU}$ & 19.89 & 21.58 & 1.69 \\
\hline 5 & $40 \% \mathrm{PU}$ & 24.58 & 23.64 & -0.94 \\
\hline 6 & $50 \% \mathrm{PU}$ & 29.69 & 28.72 & -0.97 \\
\hline
\end{tabular}

The effective flexural strength of IPN glass fiber composite with Polyurethane up to about $50 \%$ by weight was numerically determined by using ANSYS. Using the FEM software ANSYS, (Figure.4(a), 4(b), 4(c), 4(d)) It was noticed that the results obtained from experimental analysis are very closer to the FEM data's. On comparison from the Table 2 , it was found that the errors associated with the FEM values with respect to the experimental value lies in between the range of \pm 3 .
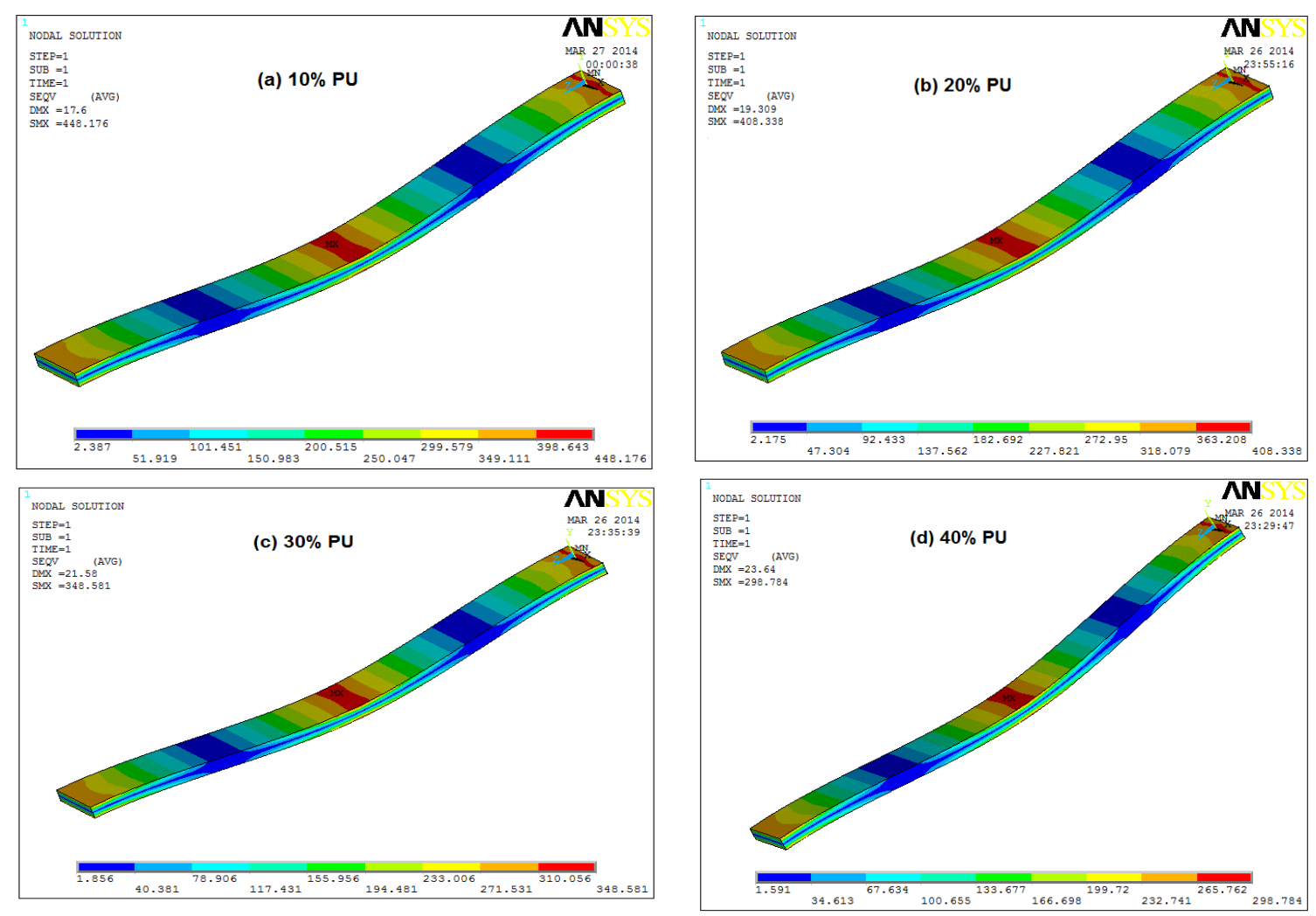

Figure 4: Deflection profiles for IPN composite with PU concentration of: (a) 10\%, (b) $20 \%$, (c) 30\%, (d) 40\%. 


\section{CONCLUSION}

From the present investigation it was concluded that VER/PU IPN Glass fiber composite exhibits better impact strength when compared to VER glass fiber composite. The improvement in the impact property was at the expense of tensile and flexural modulus. The experimental results were also compared with analytical values by Finite Element Analysis. The Analysis showed good agreement with experimental values.

\section{BIBLIOGRAPHY}

[1] WANG, T., CHEN, S., WANG, Q., et al,“Damping analysis of polyurethane/epoxy graft interpenetrating polymer network composites filled with short carbon fiber and micro hollow glass bead", Materials and Design, v.31, pp. 3810-3815, Sept 2010.

[2] RAYMOND, M.P, BU, V.T., "Epoxy/castor oil graft interpenetrating polymer networks”, J Applied Polymer Science, v.70, pp. 1649-59, Nov 1998.

[3] ATHAWALE, V. D., RAUT, S.S., "New interpenetrating polymer networks based on uralkyd/poly(glycidyl methacrylate)", European Polymer Journal, v.38, pp. 2033-2040, Oct 2002.

[4] HUA, F. J.., HU, C. P., "Interpenetrating polymer networks of epoxy resin and urethane acrylate resin: 2. Morphology and mechanical property”, European Polymer Journal, v. 36, pp. 27-33, Jan 2000.

[5] SULTANIAA, M., YADAWB, S.B., RAI, J.S.P., et al., "Laminates based on vinyl ester resin and glass fabric: A study on the thermal, mechanical and morphological characteristics", Materials Science and Engineering A, v. 527, pp. 4560-4570, April 2010.

[6] HAG, N., HARRISON, P. “Corrosion Preventing and Control”, Corrosion Policy \& Oversight v. 43, pp. 162-165, April 1996.

[7] Editoria, Materials today, http://www.reinforcedplastics.com. Accessed in MAY 2009.

[8] CHATTOPADHYAY, D.K., RAJU, K.V.S.N., "Structural engineering of polyurethane coatings for high performance applications", Prog. Polym. Sci. v. 32, pp. 352-418, March 2007.

[9] CLEMITSON IR. Castable polyurethane elastomers, London, CRC Press, May 2008.

[10] SURESH, G., JAYAKUMARI, L.S. "Evaluating the mechanical properties of E-Glass fiber/carbon fiber reinforced interpenetrating polymer networks", Polímeros, v. 25, pp. 49-57, Jan 2015.

[11] SURESH, G., JAYAKUMARI, L.S. "Analyzing the mechanical behavior of E-Glass fibre reinforced interpenetrating polymer network composite pipe", Journal of composite materials, v. 50, pp. 3053-3061, Sept 2016.

[12] CHEN, C.H., MA, C.C.M. "Pultruded fibre - reinforced PMMA / PU IPN composites : processability and mechanical properties"., Composites Part A, v. 28A, pp. 65-72, Dec 1997.

[13] MASARU ZAKO, YASUTOMO UETSUJI, TETSUSEI KURASHIKI.,"Finite element analysis of damaged woven fabric composite materials", Composites Science and Technology, v. 63, pp. 507-516, Mar 2003.

[14] NAHAS, M.N., ALZAHRANI, M.A., "Research Article: Restoration of Natural Frequency of Cracked Cantilever Beam Using CNT Composite Patch: A Finite Element Study", Mathematical Problems in Engineering, v.13, Nov 2013.

[15] ZHANG, Y.X., YANG, C.H. "Recent developments in finite element analysis for laminated composite plates", Composite Structures, v. 88, pp. 147-157, March 2009.

[16] IBRAHIM FADIL SOYKOK, ONUR SAYMAN, MUSTAFA OZEN, BEHIYE KORKMAZ., "Failure analysis of mechanically fastened glass fiber/epoxy composite joints under thermal effects", Composites: Part B, v. 45, pp. 192-199, Feb 2013.

[17] ZAKO, M., UETSUJI, Y., KURASHIKI, T., "Finite element analysis of damaged woven fabric composite materials", Composites Science and Technology, v. 63, pp. 507-516, March 2003.

[18] ANSYS Advanced Analysis Techniques Guide, http://www.ansys.com, Accessed in August 2010.

[19] QIN, C.L., CAI, W.M., CAI, J. "Damping properties and morphology of polyurethane/vinyl ester resin interpenetrating polymer network", Materials Chemistry and Physics, v. 85, pp. 402-409, June 2004. 